\title{
Targeting fundamental pathways to disrupt Staphylococcus aureus survival: clinical implications of recent discoveries
}

\author{
Isaac P. Thomsen ${ }^{1}$ and George Y. Liư ${ }^{2}$ \\ 'Department of Pediatrics, Division of Pediatric Infectious Diseases, and Vanderbilt Vaccine Research Program, Vanderbilt \\ University Medical Center, Nashville, Tennessee, USA. Division of Pediatric Infectious Diseases and Research Division of \\ Immunology, Department of Biomedical Sciences, Cedars-Sinai Medical Center, Los Angeles, California, USA.
}

The emergence of community-associated methicillin-resistant Staphylococcus aureus during the past decade along with an impending shortage of effective antistaphylococcal antibiotics have fueled impressive advances in our understanding of how $S$. aureus overcomes the host environment to establish infection. Backed by recent technologic advances, studies have uncovered elaborate metabolic, nutritional, and virulence strategies deployed by $S$. aureus to survive the restrictive and hostile environment imposed by the host, leading to a plethora of promising antimicrobial approaches that have potential to remedy the antibiotic resistance crisis. In this Review, we highlight some of the critical and recently elucidated bacterial strategies that are potentially amenable to intervention, discuss their relevance to human diseases, and address the translational challenges posed by current animal models.

Conflict of interest: IPT serves as an investigator on studies funded by ClaxoSmithKline and as a consultant for Horizon Pharma and Achaogen Inc.

License: This work is licensed under the Creative Commons Attribution 4.0 International License. To view a copy of this license, visit http:// creativecommons.org/licenses/by/4.0/

Published: March 8, 2018

Reference information: JCI Insight. 2018;3(5):e98216. https:// doi.org/10.1172/jici.insight.98216

\section{Introduction}

The progressive increase in the prevalence of antibiotic resistance within circulating strains of Staphylococcus aureus is well documented (1). The frequency of resistance to drugs, such as clindamycin, considered to be the mainstays of antistaphylococcal therapy has increased rapidly in recent years (2), and resistance to oritavancin, the most recently US-approved drug to combat methicillin-resistant $S$. aureus (MRSA), has already been reported (3). A clear need exists for the development of novel preventive and therapeutic approaches to combat this pathogen.

The majority of available antistaphylococcal antimicrobial agents exert their bactericidal or bacteriostatic effects by a limited number of mechanisms (Table 1). In fact, all current first-line and second-line therapies (based on expert guidance, refs. 4-6) against $S$. aureus, both MRSA and methicillin-sensitive $S$. aureus (MSSA), exert their antimicrobial effect via one of three mechanisms: disruption of the cell wall and/or cell membrane ( $\beta$-lactams, glycopeptides, lipopeptides), ribosome-targeted interference of protein synthesis (tetracyclines, macrolides, lincosamides, oxazolidinones), or inhibition of nucleotide production by disrupting folate synthesis (trimethoprim-sulfamethoxazole [TMP-SMX]) (7). In parallel, antibiotic use has selected for $S$. aureus strains with efficient strategies to counteract each mode of attack. A substantial number of important discoveries in the last decade have provided new insights into fundamental mechanisms, such as nutrient acquisition, key metabolic pathways, and evasion of host defenses, that allow $S$. aureus survival in the host. In this Review, we highlight some of these notable discoveries and discuss their clinical relevance and potential implications for developing novel interventions against this important pathogen.

\section{Metabolic and nutritional pathways}

The antimicrobial agents TMP and SMX inhibit necessary steps in folate synthesis (8), a key $S$. aureus metabolic pathway. These agents are typically used synergistically and exemplify the treatment potential of targeting $S$. aureus metabolism. Despite the great success of TMP-SMX, which has been used since the 1960s (9), no other $S$. aureus metabolic pathway-disrupting antimicrobial agents are currently approved. However, several recent studies provide promising targets of intervention in this area (Figure 1).

Metal acquisition and competition. A variety of metal ions are essential nutrients for $S$. aureus replication and survival in the host. There is a conflict between metal ion acquisition by the pathogen 
Table 1. Targets of intervention against $S$. aureus in current clinical use

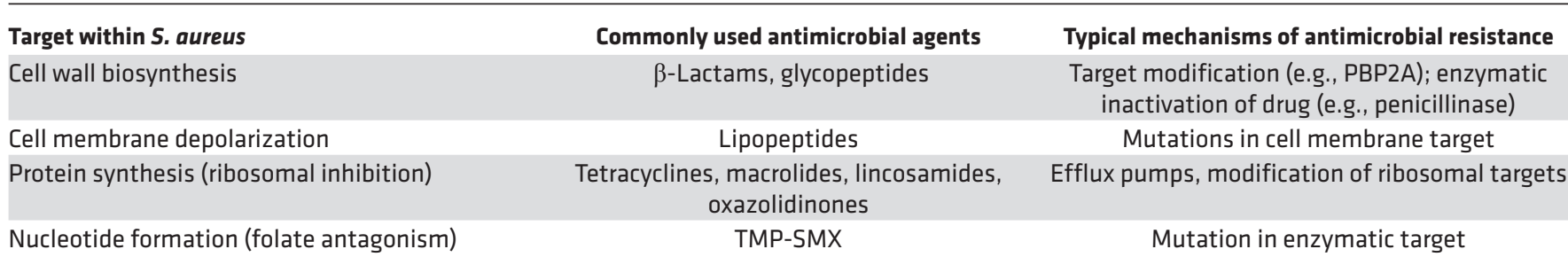

and sequestration by the host. The ability to overcome host sequestration is critical for staphylococcal survival, and this balance, theoretically, could be perturbed to favor the host. Perhaps the best-studied example of this host-pathogen interaction is the acquisition of iron by $S$. aureus via uptake of host heme proteins, such as hemoglobin. In $S$. aureus, heme uptake is mediated by the iron-regulated surface determinant (Isd) system, which includes a surface receptor for hemoglobin IsdB. Disruption of the Isd system severely attenuates infection in a variety of in vivo models (10-12). Importantly, IsdB represents an example of $S$. aureus' evolution as a human-specific pathogen. IsdB preferentially binds human hemoglobin (13); therefore, the Isd system is a logical target for intervention against $S$. aureus. While active IsdB immunization of patients prior to thoracic surgery was not efficacious in a phase III clinical trial (14), other approaches to manipulate the heme biosynthesis pathway may hold promise. Recently, small-molecule activation of CgoX, a critical heme biosynthesis enzyme, was shown to cause accumulation of coproporphyrin III and render $S$. aureus susceptible to killing by light exposure (photodynamic therapy) in a murine soft-tissue infection model (15), representing the first-known example of photosensitization of $S$. aureus by a small molecule.

The uptake of other cations, such as manganese and zinc, is also essential for $S$. aureus virulence (16). The manganese transporter MntABC is necessary for bacterial growth and resistance to oxidative stress, in part due to the critical role of manganese as a cofactor for superoxide dismutases A and M (SodA, SodM), with SodM being unique to $S$. aureus (17). Diminished manganese uptake renders MntABC mutants highly sensitive to killing by human neutrophils (18) and growth deficient (19). Moreover, MntABC deficiency in invasive clinical isolates similarly renders these strains sensitive to oxidative stress (20). MntC is the manganese-binding surface component of MntABC; it directly competes with host calprotectin, a critical mediator of metal sequestration (21), and vaccination against $\mathrm{MntC}$ is protective in a murine model of $S$. aureus bacteremia (22). Given the importance of manganese uptake for $S$. aureus virulence, MntC has recently been included in both passive and active $S$. aureus immunization regimens currently under investigation in mice and humans, respectively $(23,24)$.

Flexible metabolism in resource-limited conditions. The remarkable ability of $S$. aureus to invade multiple tissues and survive a variety of host stressors is due, in part, to a flexible metabolism. The organism's ability to utilize multiple metabolic substrates is a critical component of pathogenesis, and interference with these pathways represents a potential intervention opportunity. For example, $S$. aureus alters carbohydrate utilization based on host conditions and is well known to facultatively ferment glucose by inducing lactate dehydrogenase in the presence of NO radicals, which are a major component of innate host defense (25). This ability to thrive in the presence of radical NO is critical for pathogenesis and depends on high level L-lactate dehydrogenase activity as well as specific glycolysis substrates. A recent study determined that $S$. aureus depends on glycolysis of hexose sugars, such as glucose and mannose, to survive in the presence of radical NO (26).

The importance of glycolysis for staphylococcal virulence, particularly in light of the discovery of highly efficient glucose transporters on the $S$. aureus surface (27), has potential to be clinically relevant, given the known increased risk of staphylococcal disease in patients with diabetes (28). Glycolysis occurs in all eukaryotes (and is a component of host defense against $S$. aureus, ref. 29); however, a specific inhibitor of $S$. aureus pyruvate kinase, which mediates the final glycolysis step, has been developed $(30,31)$. As patients with uncontrolled diabetes have increased levels of circulating glucose, specific inhibition of $S$. aureus glycolysis may prevent the pathogen from leveraging this metabolic imbalance, especially if the glycolytic dependence of $S$. aureus occurs to the same degree in humans and mice. However, the contribution of excess glucose 

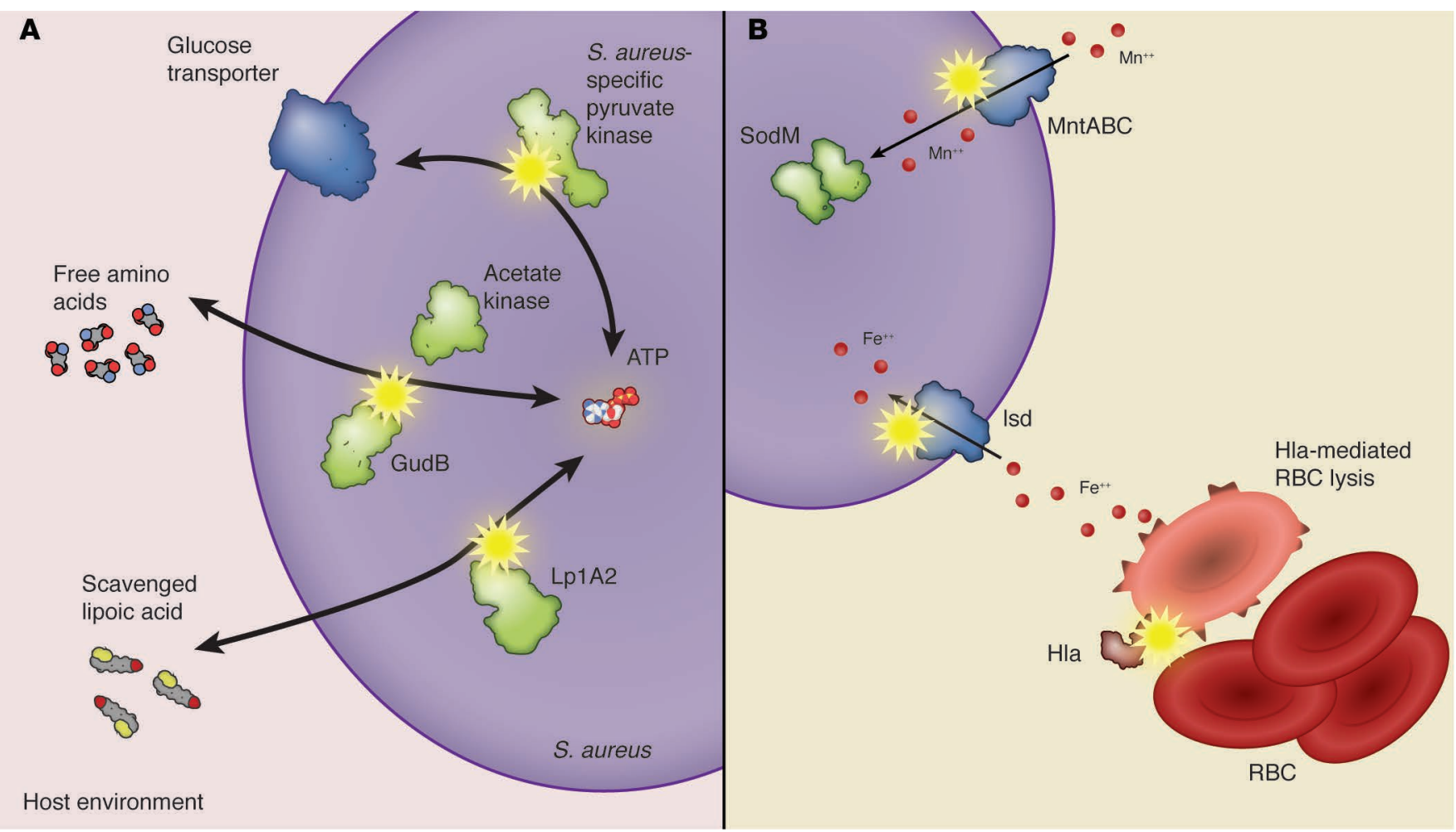

Figure 1. S. aureus employs a variety of strategies to ensure adequate nutrition and metabolic function in resource-limited host environments. Recent insights into these pathways have revealed potential targets of intervention, as disruption of nutrient acquisition and energy production may serve to attenuate virulence. (A) A summary of metabolic adaptations of interest. S. aureus is able to utilize diverse sources of substrates to generate ATP. S. aureus produces a glutamate dehydrogenase (GudB) and an acetate kinase that can catabolize free amino acids from the host (32). Additionally, S. aureus produces a pyruvate kinase and glucose transporters that facilitate glycolysis (27-31) and is able to scavenge free lipoic acid (33). (B) Numerous critical steps have been identified for the acquisition of host metals by $\mathrm{S}$. aureus. The MntABC transporter delivers manganese, which, among other roles, is a required cofactor for superoxide dismutase (17-20). $\alpha$-Hemolysin-mediated (Hla-mediated) RBC lysis liberates host heme, resulting in a bacterial iron source via the Isd system (10-13). Illustrated by Rachel Davidowitz.

warrants further investigation, as other factors, such as compromised vasculature, host cell physiology, and immune compromise, likely contribute to the risk of $S$. aureus disease in patients with diabetes

Equally important for host tissue invasion and deep-seated abscess formation may be the ability of the S. aureus to catabolize amino acids in the absence of available glucose. The glutamate dehydrogenase GudB and an acetate kinase that is capable of generating ATP from amino acids were recently discovered and shown to be necessary for $S$. aureus growth in the absence of glucose (32). Disruption of this pathway likely would not affect colonization or superficial infection but could limit the organism's ability to persist during tissue hemoinvasion. Similarly, S. aureus produces an enzyme, Lp1A2, that is not critical for in vitro growth but is required for invasion in vivo (33). This enzyme allows scavenging of lipoic acid, an enzyme complex cofactor critical for intermediary metabolism, in conditions in which free lipoic acid is limited. This serves as another example of how the infection site niche dictates the diverse mechanisms of growth used by $S$. aureus. As focal molecular methods of interference, such as small-molecule inhibitors, improve, these important pathways become increasingly clinically relevant as therapeutic targets of intervention against $S$. aureus.

\section{Evasion and manipulation of host defenses}

$S$. aureus has evolved a wealth of diverse strategies to evade natural host defenses. While $S$. aureus defenses have been well reviewed in recent years, this Review will focus on recent discoveries with high clinical relevance and logical targets for intervention against the pathogen (Figure 2).

Protein $A$ and other cell-surface effectors of immune interference. Numerous explanations for the long list of failed $S$. aureus vaccine attempts throughout the past century have been hypothesized; however, one of the foremost factors may be staphylococcal protein A (SpA). SpA and additional surface-localized factors, such as staphylokinase (Sak), staphylococcal superantigen-like protein 10 (SSL10), and staphylococcal binder of Ig 


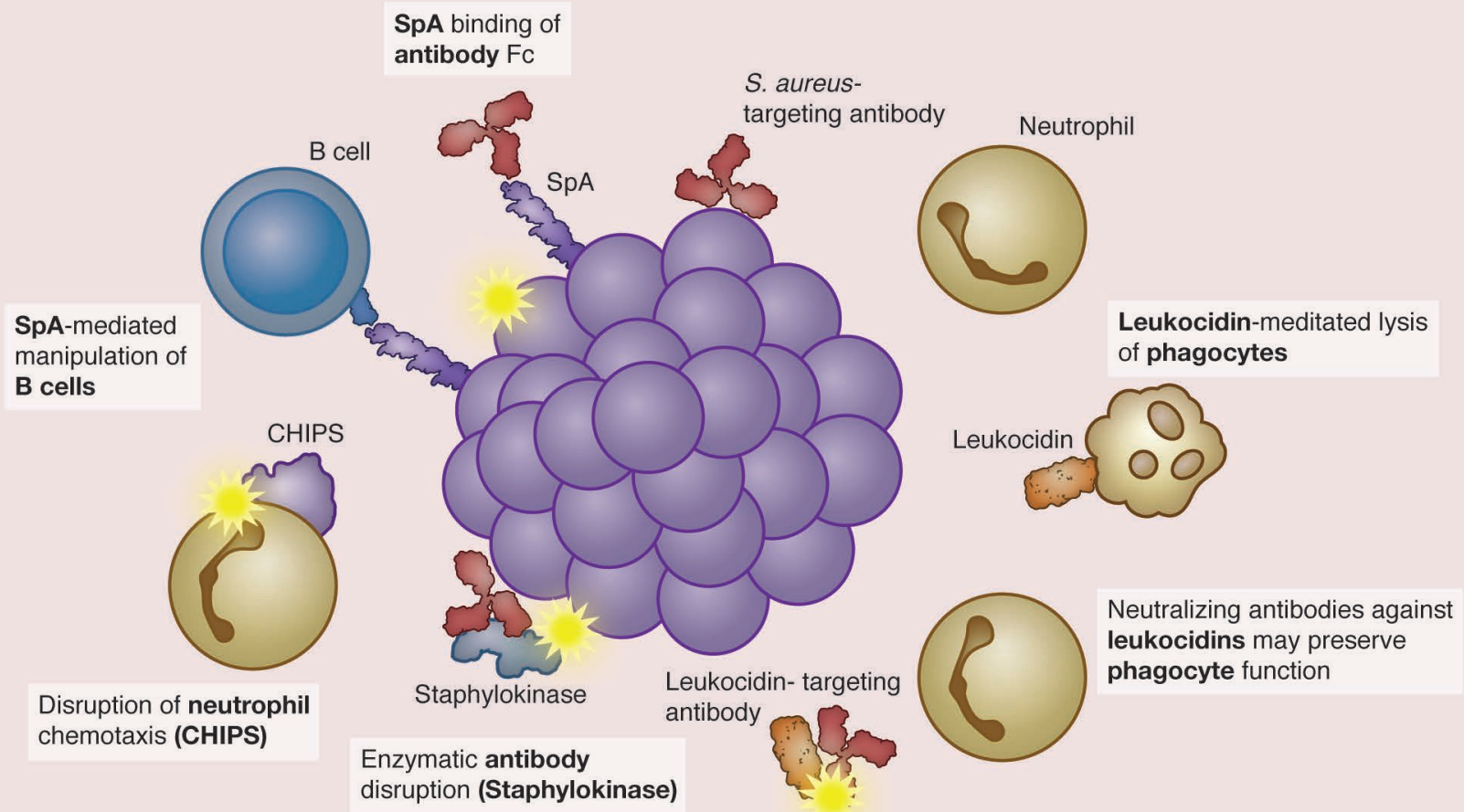

Figure 2. Efficient evasion of both innate and adaptive host defense is paramount to the ability of $\mathbf{S}$. aureus to invade and persist in humans. Staphylococcal immune evasion is mediated by several distinct pathways that appear to have high relevance in the setting of human disease and, therefore, represent potential therapeutic or preventive targets. The neutrophil is the primary mediator of innate antistaphylococcal host defense (47), and $S$. aureus expresses numerous proteins capable of interfering with neutrophil function, such as disruption of chemotaxis (CHIPS, refs. 79, 80) or potent lysis (the leukocidins, refs. 59-68) and phenol-soluble modulins (89-94). Human antibodies are capable of neutralizing leukocidin-mediated lysis and represent a potential target for intervention (74-76). Adaptive immunity is disrupted by the pathogen via numerous virulence factors, including staphylokinase (46) and staphylococcal protein A (SpA), which has several known functions, including avid binding of IgG Fc as well as manipulation of B cell responses (34-39). Illustrated by Rachel Davidowitz.

(Sbi), function together to profoundly interfere with antibody binding, complement deposition and activation, and opsonophagocytosis. SpA binds the Fc fragment of human IgG with high affinity, forms a complex with human Fab, and interferes with classical complement activation. More recently, however, the immunologic effects of SpA have been shown to extend beyond interactions at the antibody-effector level. SpA binding to B cell receptors on peripheral murine B cells induces substantial B cell apoptosis in vivo (34), and this apoptotic B cell targeting by SpA is potent and dose dependent (35). In both murine and guinea pig models, WT SpA suppresses B cell responses and leads to clonal apoptosis and prevention of memory responses, both of which are restored during infection with $\mathrm{SpA}$ mutant strains (36-38). Finally, $\mathrm{SpA}$ is superantigenic, and apparently human B cells are biased toward SpA at the expense of other important antigens, severely limiting host response (39). Despite structural similarities with other staphylococcal superantigens, SSL10 lacks superantigen characteristics. Recently, SSL10 was shown to bind the heavy and light chains of human IgG (40) and to prevent complement component $\mathrm{C} 1 \mathrm{q}$ deposition (41), thereby inhibiting classical complement activation. SSL10 appears to be highly conserved across $S$. aureus isolates (42). Sbi is present among diverse $S$. aureus lineages, including clinical isolates (43), and binds human IgG Fc in a Fab-independent manner (44). Sbi appears to also be released from the cell surface, and this form is capable of activating and consuming complement (45). Finally, Sak potently activates human plasminogen on the $S$. aureus surface, leading to cleavage of two critical components of opsonization, IgG and C $3 b$ (46). Taken together, these recent data strongly suggest that these anti-antibody factors hinder the typical antibody-antigen interactions that are highly successful for vaccines targeting other bacteria, such as Streptococcus pneumoniae and Haemophilus influenza, and, therefore, conventional vaccine strategies are less likely to be realistic for $S$. aureus disease prevention in humans.

Toxin-mediated targeting of host cells. Neutrophils are critical for human host defense against $S$. aureus, as patients with neutrophil defects have a severe burden of staphylococcal disease (47). It is no coincidence, 
then, that $S$. aureus employs a variety of important virulence factors that target host phagocytes, including pore-forming toxins, particularly the bicomponent leukocidins (LukAB [also known as LukGH], Panton-Valentine leukocidin [PVL], LukED) and the $\gamma$-hemolysins (HlgAB and HlgCB). The leukocidin family toxins are secreted as monomers, which dimerize and oligomerize on the surface of host cells (particularly phagocytes) to form a pore, resulting in inflammasome activation and cell lysis (48). These toxins exert their effect away from the $S$. aureus surface; therefore, they have potential to be targeted with antibody-based interventions, as the effects of surface factors mentioned above, such as SpA and Sbi, may be at least partially avoided.

$\alpha$-Hemolysin (Hla) is a pore-forming toxin with a high tropism toward erythrocytes, and, along with LukED and $\mathrm{HlgAB}$, it appears to promote $S$. aureus growth by providing access to host hemoglobin and, therefore, iron $(49,50)$. Hla is also capable of lysing host endothelial cells and leukocytes, both of which express of the toxin's receptor A disintegrin and metalloproteinase 10 (ADAM10) (51, 52). Hla-mediated endothelial lysis leads to vascular permeability and exacerbation of sepsis in murine models (53), and this permeability may allow $S$. aureus dissemination from the bloodstream into host tissues. The Hla-ADAM10 interaction was recently shown to mediate enhanced $S$. aureus survival in the presence of murine mast cells (54) and to disrupt platelet function and neutrophil signaling (55). Serologic studies indicate that Hla is expressed during human infections, including pneumonia (56) and bacteremia (57), and this complex toxin is a virulence factor being explored for vaccine constructs currently in development (58).

The host receptors for the bicomponent leukocidins have recently been identified (59-62) and appear to have substantial species specificity. For example, LukAB is highly lytic to human phagocytes but only weakly toxic to murine cells due to species-specific differences in the LukAB receptor CD11b $(60,63,64)$. Similarly, PVL and HlgCB do not bind murine C5aR1/2, the myeloid receptor for these toxins $(65,66)$. The species-specific disparity in receptor binding has likely led to an underestimation of the importance of these toxins for human disease. Notably, LukAB, PVL, and HlgCB are moderately toxic to leporine leukocytes, suggesting that rabbits may be a more appropriate model for assessing these human-evolved factors in vivo (63).

Numerous groups have demonstrated that the effects of leukocidins are not limited to pore formation and cell lysis. At sublytic concentrations, LukAB and PVL alter cellular signaling by inflammasome activation, leading to IL-1 $\beta$ secretion $(67,68)$, and PVL is capable of priming and activating human neutrophils, resulting in enhanced phagocytic function (69). In addition, toxin monomers appear to antagonize their receptors, which may interfere with phagocyte recruitment and function $(61,62)$. Further, the leukocidins have been identified in noncanonical pairs (e.g., HlgA-LukD), and these noncanonical toxin units can antagonize the cytotoxicity of canonical toxin pairs, suggesting a broader complexity of leukocidin biology than previously appreciated (70-72).

The potential clinical importance of leukocidin family toxins is underscored by their expression during natural human infection. LukAB, in particular, is clearly expressed during invasive human disease, as evidenced by a significant rise in anti-LukAB IgG levels in both recovering children and adults $(73,74)$ and the purification of human LukAB-neutralizing monoclonal antibodies that recognize diverse epitopes following invasive disease (75). LukAB is also the dominant toxin secreted in vitro under conditions designed to recapitulate the host environment (76-78). These recent findings strongly suggest that the leukocidins warrant continued investigation as potential targets of intervention, particularly for the amelioration or prevention of invasive disease and bloodstream infections.

Phagocyte interference. In addition to lysing host cells, $S$. aureus is capable of disrupting neutrophil function at each step of the innate host response. Chemotaxis inhibitory protein of $S$. aureus (CHIPS) is a prominent factor involved in staphylococcal interference with proper neutrophil migration and was shown to potently interfere with chemoattractants, such as C5a and formylated peptides (79). Importantly, CHIPS exhibits a marked specificity for human neutrophils (80). Similar chemotactic inhibitory functions have since been reported for inhibitors of formyl peptide receptor-like 1, another strong mediator of phagocyte homing $(81,82)$. SSL5 potently inhibits in vitro chemokine-induced activation of human leukocytes and selectin-dependent neutrophil rolling, thereby adding to the broad armamentarium of antiphagocyte functions of $S$. aureus (83).

$S$. aureus also employs phenol-soluble modulins (PSMs) for antiphagocyte defense that have proven to be important for virulence in animal models, though the clinical significance of PSMs remains to be determined. PSMs are small peptides that directly target host cells, including phagocytes, and are capable of numerous functions, including host cell activation and cell lysis (89). PSMs are required for virulence in 
multiple animal models of $S$. aureus infection, including both noninvasive (cutaneous infection, refs. 89-91) and invasive (osteomyelitis, refs. 92, 93; bacteremia, ref. 89) diseases. PSMs have diverse and complex functions, ranging from cellular recruitment (94) to biofilm support (see below). Notably, all PSMs are exported through a single cassette transporter; therefore, inhibition of this transporter would fully eliminate PSM production (95), supporting this peptide transporter as a point of intervention to curb $S$. aureus pathogenesis.

$T$ cell interference. In addition to interfering with host antibody defense, $S$. aureus deploys multiple strategies to undermine $\mathrm{T}$ cell defenses. Expression of staphylococcal superantigens that induce $\mathrm{T}$ cell anergy and/or deletion has been well described (96), though it is not fully understood if T cell targeting contributes to human infection, because staphylococcal superantigens exhibit species-specific tropism for human HLA molecules. S. aureus also secretes a major histocompatibility complex-like molecule that is thought to drive T cell differentiation toward a Th2 phenotype (97) and toxins that induce T cell cytolysis or apoptosis (59, 98), both of which could adversely affect host protective memory.

$S$. aureus has recently been shown to undermine development of Th17 cells (99), which may be critical for human defense against $S$. aureus infection, as IL-17-deficient patients with hyper-IgE syndrome have increased susceptibility to $S$. aureus infections (100). Induction of Th17 cells requires expression of Th17-polarizing cytokines by antigen-presenting cells (101); however, S. aureus limits release of these cytokines via $O$-acetylation of its cell wall peptidoglycan, which effectively blocks lysozyme-mediated degradation of peptidoglycan $(102,103)$ and release of embedded proinflammatory pattern recognition molecular patterns (104). By limiting the Th17 memory response, $S$. aureus can effectively reinfect the same host without long-term immunity (99). Patients with $S$. aureus bloodstream infection only mount a modest Th17 response (105). This absence of a robust Th17 response in humans after natural $S$. aureus infection suggests $S$. aureus vaccine would benefit from the inclusion of a Th17 adjuvant (Figure 3).

\section{Adaptations to the host environment}

The ability of $S$. aureus to establish infection and persist in a wide variety of host tissues is remarkable. This flexibility is due, in part, to the immune evasion and nutrient acquisition pathways discussed above. Several additional mechanisms have recently been described that detail additional ways that this complex organism manages not only to survive, but also to thrive in resource-limited or toxic host conditions.

Maintaining oxygen balance: antioxidant defenses and virulence despite hypoxia. ROS generated by neutrophils and myeloid cells are a major barrier to successful $S$. aureus infection. ROS are generated upon bacterial phagocytosis by NADPH oxidase and myeloperoxidase and synergize with reactive nitrogen species to induce direct or indirect killing of pathogens. $S$. aureus responds to these insults with an antioxidant defense consisting of ROS sensors, antioxidant molecules, and oxidative repair enzymes. The antioxidant molecules and enzymes commonly expressed upon exposure to ROS are reviewed elsewhere (106). Staphyloxanthin, the eponymous feature of $S$. aureus, is a C30 triterpenoid carotenoid thought to scavenge free radicals with conjugated double bonds (107) and promote resistance to cationic antimicrobial peptide killing by increasing bacterial membrane rigidity (108). Staphyloxanthin enhances $S$. aureus survival in WT mice but not in NADPH oxidase-deficient mice $(109,110)$, and inhibition of staphyloxanthin biosynthesis reduces $S$. aureus viability in the host, thereby corroborating the antioxidant function of the molecule in pathogenesis (110-112). Moreover, staphyloxanthin inhibition in these studies was achieved via a small-molecule inhibitor, suggesting potential therapeutic application of such a target. $S$. aureus also generates NO, via a NO synthase, as an oxidative product that unexpectedly protects the pathogen against ROS, antimicrobial peptides, and neutrophils (113). NO or downstream metabolites may be protective due to scavenging of HOCL by nitrite, which leads to generation of less ROS (114). Notably, the formation of nitrite downstream of bacterial NO synthesis also appears to contribute to $S$. aureus aerobic respiration by stimulating quinol oxidase, further highlighting the importance of NO synthase (115).

The $S$. aureus antioxidant defense represents an intriguing target for human therapeutics based on the heightened susceptibility of NADPH oxidase-deficient patients to $S$. aureus infections (116). Specific antioxidant targets have been confirmed to contribute to staphylococcal pathogenesis or colonization and include Sod (117), catalase (118, 119), alkyl hydroperoxide reductase (119), and staphyloxanthin (109, 110) (Figure 3). An alternative approach to increase oxidative killing of $S$. aureus is to boost the oxidative function of host phagocytes. In neutrophils, increasing angiotensin-converting enzyme expression has been shown to boost oxidative killing (120). Targeting both bacterial antioxidant defense and boosting host oxidative function represents a potential synergistic approach to combat $S$. aureus. 


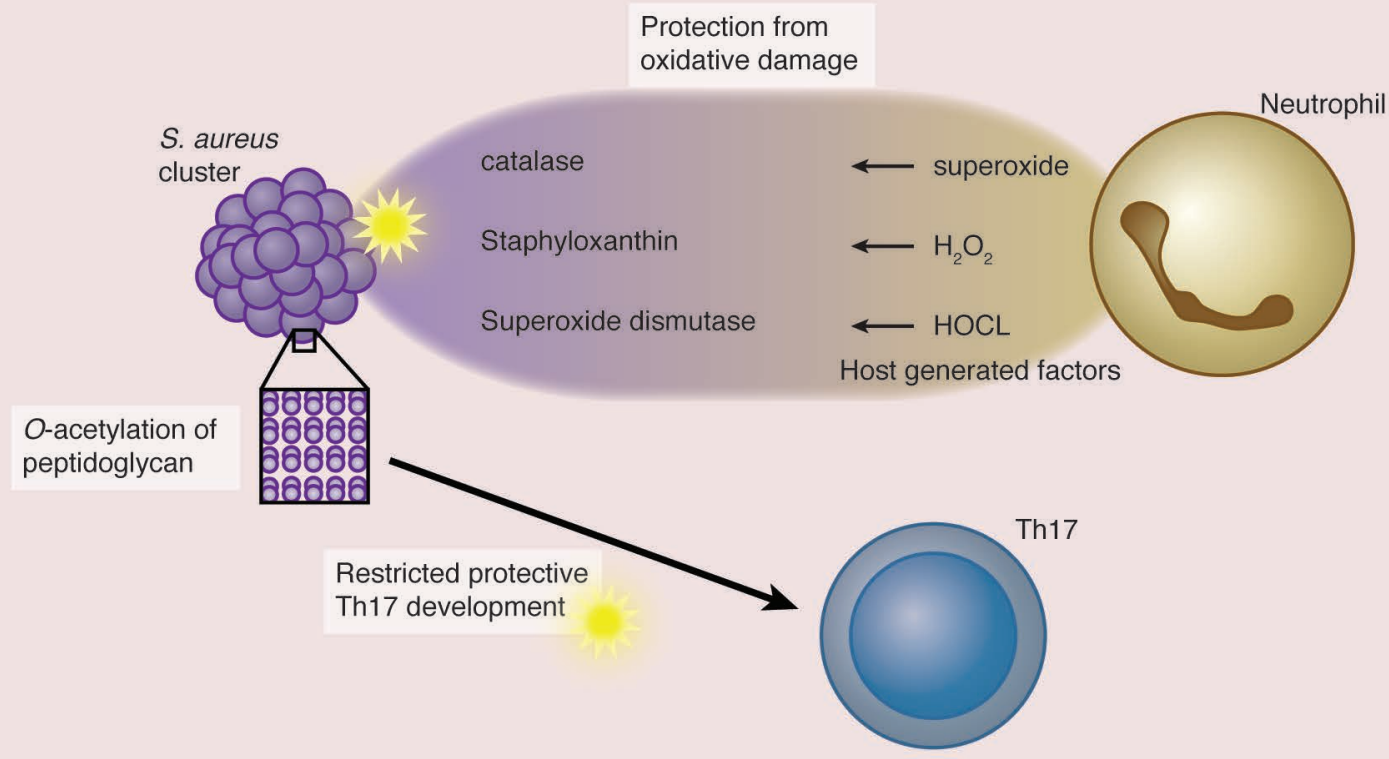

Figure 3. Human immunodeficiency conditions that associate with susceptibility to $S$. aureus infections suggest chinks in the staphylococcal defense that are potentially amenable to intervention. The epidemiology of hyper-IgE syndrome patients suggests that $S$. aureus is susceptible to Th17-mediated killing. Staphylococcal counterstrategies to avoid a Th17 response consist of $O$-acetylation of cell wall peptidoglycan to limit the release of pattern-associated molecular patterns and dampen development of a protective Th17 response (99). Predisposition to S. aureus infection in patients with chronic granulomatous disease hints at imperfect staphylococcal protection against ROS in normal hosts. This bacterial weakness could be further exploited by strategies that block staphylococcal antioxidant defenses, such as staphyloxanthin (109, 110), catalase, and superoxide dismutase (117, 118). Illustrated by Rachel Davidowitz.

At the opposite end of the oxygenation spectrum, recent studies have elucidated mechanisms that support $S$. aureus virulence in response to host tissue hypoxia. In a variety of end-organ invasion sites, the organism must maintain virulence in the setting of reduced oxygen tension (121). A recent study used transposon sequence analysis in a robust murine model of osteomyelitis (92) to show that the two-component gene regulatory system SrrAB (122) is critical for staphylococcal survival in hypoxic bone (123). Further, the supernatant from $S$. aureus cultures grown under hypoxic conditions had markedly increased cytotoxicity against a variety of murine and human cells, and SrrAB appears to regulate both hypoxia-induced toxin production and quorum sensing in response to varying oxygen tension. Interestingly, SrrAB overexpression has been shown to repress SpA production and decrease virulence in a rabbit endocarditis model, highlighting the complex relationship between $S$. aureus regulatory systems (124). As both human and murine bones are similarly hypoxic environments $(125,126)$, these collective observations have high potential clinical importance in understanding the virulence of $S$. aureus in invasive infections, such as osteomyelitis.

Biofilm and persister formation. S. aureus employs several additional strategies for survival in a hostile host environment that represent potential opportunities for therapeutic intervention. The biofilm-forming ability of $S$. aureus is well described, particularly as a component of chronic infections (127). The congregation of organisms embedded in an extracellular matrix allows the maintenance of an environment that is relatively impenetrable to standard antibiotic therapies and host defenses. Biofilm formation appears to be under complex genetic regulation, as numerous gene regulatory systems have been implicated in this process (128). Based on murine models, the staphylococcal accessory regulator A $(\operatorname{sar} A)$ is a promising target for intervening in biofilm production. sarA mutations reduce biofilm viability, allowing enhanced antimicrobial susceptibility, thereby improving in vivo outcomes $(129,130)$. The quorum-sensing agr locus also regulates biofilm maturation $(122,131)$, and the recent identification of 
additional biofilm regulators, such as $x \operatorname{erC}(132)$ and $\mathrm{rob}$ (a putative biofilm repressor) (133), suggest that more work is needed to fully understand biofilm regulation before designing fundamental interventions at the genetic level.

Structurally, biofilm formation and maturation require several components that have been recently elucidated and may represent opportunities to prevent or disrupt biofilm formation. A heavily studied component of $S$. aureus biofilm adhesion is poly- $N$-acetylglucosamine (PNAG), also known as polysaccharide intercellular adhesin (PIA). PNAG is a critical adhesin in a variety of in vitro and in vivo biofilm models (134), and human mAbs to this antigen have been shown to exhibit opsonophagocytic activity (135). PNAG is currently being considered as a vaccine target for investigation in humans (136), though it is not produced by some biofilm-forming clinical $S$. aureus strains (137). The PSM peptides (discussed above) also appear to be critical for biofilm maturation, as PSM mutants exhibit deficient biofilm structure and expansion $(138,139)$.

Antimicrobial therapy also promotes selection of $S$. aureus persister cells, which provide a survival advantage in the presence of antistaphylococcal therapeutics and contribute to chronic or recalcitrant $S$. aureus infections (140). Encouragingly, a relatively new class of antimicrobial agents, the acyldepsipeptides (141), has been shown both to effectively kill $S$. aureus persister cells by activating bacterial proteases and to render persisters susceptible to other antimicrobials (142). The antibiotic resistance profiles of biofilms and persister cells are nearly equivalent, suggesting that biofilms are likely enriched with persister cells (143). This intersection of staphylococcal strategies to survive in the presence of antimicrobials warrants further study and may be a high yield area of potential intervention against the pathogen for a variety of clinically important phenotypes, such as chronic hardware infections, endocarditis, and others.

Manipulation of host coagulation. In addition to providing hemostasis, the coagulation system represents an important component of innate host defense that prevents pathogen dissemination. $S$. aureus has evolved remarkable strategies to hijack the coagulation cascade, allowing the organism to convert this host defense mechanism into a protective fibrin sheath that supports survival and replication (144). This process is primarily mediated by coagulase (Coa) and von Willebrand factor-binding protein (vWbp) (145), both of which bind and activate prothrombin, resulting in thrombin complexes that cleave fibrinogen to generate a bacterial-derived coating of host fibrin (146). Importantly, while Coa and vWbp both activate prothrombin, they are both required for virulence in models of bacteremia and abscess formation, indicating distinct functions in the manipulation of host coagulation (147). The surface component clumping factor A (ClfA) is the major fibrinogen-binding protein of $S$. aureus and also appears to contribute to coagulation manipulation (148). Recent data indicate that all three proteins, Coa, vWbp, and ClfA, are necessary for virulence in animal models of invasive and noninvasive staphylococcal disease $(149,150)$

Coa and vWbp activity are important for $S$. aureus virulence in a variety of models, indicating that these factors are worthy targets for potential intervention against the organism. Antibodies against Coa and $\mathrm{vWbp}$ are capable of protecting against bacteremia and abscess formation in murine models (147), and a subunit vaccine has shown protective efficacy in mice (151). The ClfA-targeting monoclonal antibody tefibazumab was evaluated as a vaccine candidate in humans and was shown to be safe but had minimal efficacy, despite promising preclinical data $(152,153)$. Finally, Coa function may also be targeted directly, as antithrombin agents were recently shown to prevent $S$. aureus endocarditis in a rat model, suggesting that thrombin inhibition may be a consideration in high-risk patients with prosthetic heart valves (154).

\section{Current challenges in the translation of basic discoveries to clinical resources}

The study of pathogenesis has enhanced the fundamental understanding of how $S$. aureus interacts with the host but ultimately is intended to improve human health. Predictable animal models of disease are paramount for basic discoveries to translate to the clinic. It has long been appreciated that animal models of $S$. aureus infection likely do not exactly recapitulate the human disease, as very high inoculums are needed to induce pathology in mice (155-157). Interestingly, certain phenotypes, such as cutaneous abscess formation, can be produced in mice with relatively similar inoculum size to that required for human infection. However, a notably larger inoculum is required to generate more immune-driven phenotypes,such as shock, in animal models. This discrepancy is likely related to increased interactions at the molecular level between humans and $S$. aureus compared with mice and $S$. aureus.

Animal models have also come under increasing scrutiny in the past decade due to their failure to resolve important $S$. aureus clinical problems. In particular, in emerging community-associated MRSA 
strains, PVL expression strongly correlates with necrotizing human diseases but is not required for pathologic phenotypes in mice (158). The long-standing controversy over the role of PVL in disease was unraveled after the discovery that PVL binds strongly to human, but not mouse, C5aR (66). The failed clinical trials of $S$. aureus component vaccines that were successfully developed in mice have also been unsettling (14) and have raised serious concerns regarding key differences between human and mouse immune responses to $S$. aureus.

Although $S$. aureus pathogenesis in mice has been increasingly well delineated, it is unclear what aspects and to what extent murine infections are relevant to human disease. High infectious inoculum is required in most animal models to induce $S$. aureus infection and could clearly alter quorum sensing and the physiologic context under which individual bacterial factors are expressed and studied for functional significance. More importantly, the concept of what defines a human-like disease phenotype remains unclear. In spite of these challenges, mouse models continue to be attractive because of the relative low cost and plethora of available tools to study complex mechanisms.

As a complement to standard mouse models, investigators have had some success modeling specific aspects of pathogenesis in other animals, such as rabbits and rats. The use of other species has not circumvented the need for high inoculums but has, in certain instances, enhanced the modeling of host-pathogen interactions, as was exemplified by evaluation of PVL in the rabbit model (159). Additionally, mice that transgenically express select human receptors provide an alternative approach for studying virulence factors with human tropism (13); however, this approach requires prior knowledge of cognate receptors for the bacterial product.

More recently, several reports have addressed modeling $S$. aureus infections in so-called "humanized" mice (160-162), which are immunocompromised animals engineered to accept human hematopoietic stem cells and subsequently develop a human immune system (163). Initial reports indicate that humanized mice in the NOD/SCID $\gamma$ (NSG) background may be an improved model, as a reduced inoculum (up to 1-2 logs lower than that required for WT mice in the soft-tissue model) is able to induce dermonecrosis. Moreover, humanized NSG mice exhibit a pathologic phenotype for factors with selective human tropism (160-162). However, the high cost; the potential confounding by nonimmune compartments, such as epithelial cells; and the incomplete humanization of the immune system, including low neutrophil counts and lack of complement, remain barriers for general acceptance of the model.

In the long term, humanized mice with extensive knockin of human genes will likely become available and more faithfully model human infection. Unfortunately, there is no timeline for when these tools may become available; therefore, more immediately feasible steps need to be taken to address the current translational dilemma. For instance, given the importance of neutrophils in $S$. aureus pathogenesis, generation of a humanized mouse with increased numbers of human-like neutrophils, such as by transgenic expression of human G-CSF, will be a major step forward. For each potential model, critical evaluation of the similarity to

\section{Table 2. Animal models of $S$. aureus infection}

\begin{tabular}{|c|c|c|c|c|}
\hline Animal model & Description & Pro & Con & Remedies \\
\hline Mice & Most commonly used model & $\begin{array}{l}\text { Well characterized; abundant } \\
\text { tools; low cost }\end{array}$ & $\begin{array}{l}\text { Require high inoculums; unclear } \\
\text { tropism issues }\end{array}$ & $\begin{array}{l}\text { Understanding differences } \\
\text { in human and murine } \\
\text { responses to S. aureus }\end{array}$ \\
\hline Other animals & Rats, rabbits, cows & $\begin{array}{l}\text { More human-like than mice for } \\
\text { select virulence studies }\end{array}$ & $\begin{array}{c}\text { Few tools; require } \\
\text { high inoculums; tropism issues }\end{array}$ & Same as in mice \\
\hline Transgenic mice & $\begin{array}{l}\text { Mice that express } \\
\text { human immune or } \\
\text { nonimmune proteins }\end{array}$ & $\begin{array}{l}\text { Addresses select tropism } \\
\text { problems; benefits of standard } \\
\text { mouse model }\end{array}$ & $\begin{array}{l}\text { High inoculums; requires prior } \\
\text { knowledge of human receptor }\end{array}$ & $\begin{array}{l}\text { Knockin all relevant } \\
\text { immune genes }\end{array}$ \\
\hline Humanized mice & $\begin{array}{l}\text { Immunocompromised mice } \\
\text { engrafted with human HSCs; } \\
\text { several models supporting } \\
\text { different levels and types of } \\
\text { immune cell engraftment }\end{array}$ & $\begin{array}{l}\text { Inoculums potentially closer to } \\
\text { human infections, depending on } \\
\text { model readout; overcome some } \\
\text { human tropism problems }\end{array}$ & $\begin{array}{l}\text { Low human neutrophil count; } \\
\text { expensive; unclear compatibility } \\
\text { between human and mouse } \\
\text { immune components }\end{array}$ & $\begin{array}{l}\text { Evolving next-generation } \\
\text { humanized mice; knockin } \\
\text { h-GCSF to address major } \\
\text { neutrophil issue in } \\
\text { modeling of } \\
\text { S. aureus infections }\end{array}$ \\
\hline
\end{tabular}

h-GCSF, human granulocyte CSF. 
human disease and possible limitations will be required, as undertaken in a recent review (164) and summarized in Table 2. More direct efforts to understand $S$. aureus-human host interactions and to identify differences between human and murine immune responses to $S$. aureus may further enhance and clarify the clinical relevance of research done in mice. A refined knowledge of the types of human $\mathrm{T}$ cell and antibody responses that are protective against $S$. aureus infection will be critical for the development of an effective human vaccine. While addressing these issues will be difficult and may require the generation of new tools, these are challenges well worth pursing to advance our understanding of $S$. aureus disease in humans.

\section{Conclusions and future perspectives}

There has been a significant expansion of $S$. aureus pathogenesis research in the past decade that has been fueled by the emergence of community-associated MRSA and increased antibiotic resistance. S. aureus metabolism, a once dormant subject, has become an active area of investigation driven by technologic advances, and many $S$. aureus pathogenic mechanisms, such as toxin-related virulence, are now understood at the level of molecular interaction with host receptors. Together, these advances have identified a plethora of potential human therapeutics, but the greater challenge in the coming years will be to validate the relevance of these targets for human diseases; to demonstrate that some of the targets, at least one or two, can be developed into cost-effective reagents as alternatives and/or adjuncts to antibiotics for treating $S$. aureus-infected patients; and to improve basic models of $S$. aureus disease for better translational value.

\section{Acknowledgments}

The authors receive support from NIH grants AI127406 (to GYL) and AI113150 (to IPT). The authors apologize to many contributors in the field whose important work could not be cited because of space limitations.

Address correspondence to: Isaac P. Thomsen, Pediatric Infectious Diseases, D-7235 MCN, 1161 21st Avenue South, Nashville, Vanderbilt University School of Medicine, Nashville, Tennessee 37232-2581, USA. Phone: 615.343.9884; E-mail: isaac.thomsen@vanderbilt.edu. Or to: George Y. Liu, Division of Pediatric Infectious Diseases, Cedars-Sinai Medical Center, 8700 Beverly Boulevard, Los Angeles, CA90048, USA. Phone: 310.423.4471; E-mail: george.liu@cshs.org.

1. Sakoulas G, Moellering RC. Increasing antibiotic resistance among methicillin-resistant Staphylococcus aureus strains. Clin Infect Dis. 2008;46 Supp1 5:S360-S367.

2. Sutter DE, Milburn E, Chukwuma U, Dzialowy N, Maranich AM, Hospenthal DR. Changing susceptibility of Staphylococcus aureus in a US pediatric population. Pediatrics. 2016;137(4):e20153099.

3. Jones RN, Moeck G, Arhin FF, Dudley MN, Rhomberg PR, Mendes RE. Results from oritavancin resistance surveillance programs (2011 to 2014): Clarification for using vancomycin as a surrogate to infer oritavancin susceptibility. Antimicrob Agents Chemother. 2016;60(5):3174-3177.

4. Liu C, et al. Clinical practice guidelines by the infectious diseases society of America for the treatment of methicillin-resistant Staphylococcus aureus infections in adults and children. Clin Infect Dis. 2011;52(3):e18-e55.

5. Holland TL, Arnold C, Fowler VG. Clinical management of Staphylococcus aureus bacteremia: a review. JAMA. 2014;312(13):1330-1341.

6. Lowy FD. Staphylococcus aureus infections. N Engl J Med. 1998;339(8):520-532.

7. Kohanski MA, Dwyer DJ, Collins JJ. How antibiotics kill bacteria: from targets to networks. Nat Rev Microbiol. 2010;8(6):423-435.

8. Proctor RA. Role of folate antagonists in the treatment of methicillin-resistant Staphylococcus aureus infection. Clin Infect Dis. 2008;46(4):584-593.

9. Pappas G, Athanasoulia AP, Matthaiou DK, Falagas ME. Trimethoprim-sulfamethoxazole for methicillin-resistant Staphylococcus aureus: a forgotten alternative? J Chemother. 2009;21(2):115-126.

10. Cheng AG, Kim HK, Burts ML, Krausz T, Schneewind O, Missiakas DM. Genetic requirements for Staphylococcus aureus abscess formation and persistence in host tissues. FASEB J. 2009;23(10):3393-3404.

11. Pishchany G, et al. IsdB-dependent hemoglobin binding is required for acquisition of heme by Staphylococcus aureus. $J$ Infect Dis. 2014;209(11):1764-1772.

12. Torres VJ, Pishchany G, Humayun M, Schneewind O, Skaar EP. Staphylococcus aureus IsdB is a hemoglobin receptor required for heme iron utilization. J Bacteriol. 2006;188(24):8421-8429.

13. Pishchany G, et al. Specificity for human hemoglobin enhances Staphylococcus aureus infection. Cell Host Microbe. 2010;8(6):544-550.

14. Fowler VG, et al. Effect of an investigational vaccine for preventing Staphylococcus aureus infections after cardiothoracic surgery: a randomized trial. JAMA. 2013;309(13):1368-1378.

15. Surdel MC, et al. Antibacterial photosensitization through activation of coproporphyrinogen oxidase. Proc Natl Acad Sci USA. 2017;114(32):E6652-E6659

16. Corbin BD, et al. Metal chelation and inhibition of bacterial growth in tissue abscesses. Science. 2008;319(5865):962-965. 
17. Garcia YM, Barwinska-Sendra A, Tarrant E, Skaar EP, Waldron KJ, Kehl-Fie TE. A superoxide dismutase capable of functioning with iron or manganese promotes the resistance of Staphylococcus aureus to calprotectin and nutritional immunity. PLoS Pathog. 2017;13(1):e1006125.

18. Coady A, et al. The Staphylococcus aureus ABC-type manganese transporter MntABC is critical for reinitiation of bacterial replication following exposure to phagocytic oxidative burst. PLoS One. 2015;10(9):e0138350.

19. Horsburgh MJ, Wharton SJ, Cox AG, Ingham E, Peacock S, Foster SJ. MntR modulates expression of the PerR regulon and superoxide resistance in Staphylococcus aureus through control of manganese uptake. Mol Microbiol. 2002;44(5):1269-1286.

20. Handke LD, Hawkins JC, Miller AA, Jansen KU, Anderson AS. Regulation of Staphylococcus aureus MntC expression and its role in response to oxidative stress. PLoS One. 2013;8(10):e77874.

21. Kehl-Fie TE, et al. MntABC and MntH contribute to systemic Staphylococcus aureus infection by competing with calprotectin for nutrient manganese. Infect Immun. 2013;81(9):3395-3405.

22. Anderson AS, et al. Staphylococcus aureus manganese transport protein $C$ is a highly conserved cell surface protein that elicits protective immunity against S. aureus and Staphylococcus epidermidis. J Infect Dis. 2012;205(11):1688-1696.

23. Begier E, et al. SA4Ag, a 4-antigen Staphylococcus aureus vaccine, rapidly induces high levels of bacteria-killing antibodies Vaccine. 2017;35(8):1132-1139.

24. Zhang J, et al. Protective efficacy and mechanism of passive immunization with polyclonal antibodies in a sepsis model of Staphylococcus aureus infection. Sci Rep. 2015;5:15553.

25. Richardson AR, Libby SJ, Fang FC. A nitric oxide-inducible lactate dehydrogenase enables Staphylococcus aureus to resist innate immunity. Science. 2008;319(5870):1672-1676.

26. Vitko NP, Spahich NA, Richardson AR. Glycolytic dependency of high-level nitric oxide resistance and virulence in Staphylococcus aureus. MBio. 2015;6(2):e00045-15.

27. Vitko NP, Grosser MR, Khatri D, Lance TR, Richardson AR. Expanded glucose import capability affords Staphylococcus aureus optimized glycolytic flux during infection. MBio. 2016;7(3):e00296-16.

28. Smit J, Søgaard M, Schønheyder HC, Nielsen H, Frøslev T, Thomsen RW. Diabetes and risk of community-acquired Staphylococcus aureus bacteremia: a population-based case-control study. Eur J Endocrinol. 2016;174(5):631-639.

29. Wickersham M, et al. Metabolic stress drives keratinocyte defenses against Staphylococcus aureus infection. Cell Rep. 2017;18(11):2742-2751.

30. Zoraghi R, et al. Identification of pyruvate kinase in methicillin-resistant Staphylococcus aureus as a novel antimicrobial drug target. Antimicrob Agents Chemother. 2011;55(5):2042-2053.

31. Zoraghi R, et al. Methicillin-resistant Staphylococcus aureus (MRSA) pyruvate kinase as a target for bis-indole alkaloids with antibacterial activities. J Biol Chem. 2011;286(52):44716-44725.

32. Halsey CR, et al. Amino acid catabolism in Staphylococcus aureusand the function of carbon catabolite repression. MBio. 2017;8:e01434-16.

33. Zorzoli A, Grayczyk JP, Alonzo F. Staphylococcus aureus tissue infection during sepsis is supported by differential use of bacterial or host-derived lipoic acid. PLoS Pathog. 2016;12(10):e1005933.

34. Goodyear CS, Silverman GJ. Death by a B cell superantigen: In vivo VH-targeted apoptotic supraclonal B cell deletion by a Staphylococcal Toxin. J Exp Med. 2003;197(9):1125-1139.

35. Goodyear CS, Sugiyama F, Silverman GJ. Temporal and dose-dependent relationships between in vivo B cell receptor-targeted proliferation and deletion-induced by a microbial B cell toxin. J Immunol. 2006;176(4):2262-2271.

36. Falugi F, Kim HK, Missiakas DM, Schneewind O. Role of protein A in the evasion of host adaptive immune responses by Staphylococcus aureus. MBio. 2013;4(5):e00575-e00513.

37. Kim HK, Falugi F, Missiakas DM, Schneewind O. Peptidoglycan-linked protein A promotes T cell-dependent antibody expansion during Staphylococcus aureus infection. Proc Natl Acad Sci USA. 2016;113(20):5718-5723.

38. Kim HK, Falugi F, Thomer L, Missiakas DM, Schneewind O. Protein A suppresses immune responses during Staphylococcus aureus bloodstream infection in guinea pigs. MBio. 2015;6(1):e02369-14.

39. Pauli NT, et al. Staphylococcus aureus infection induces protein A-mediated immune evasion in humans. J Exp Med. 2014;211(12):2331-2339.

40. Patel D, Wines BD, Langley RJ, Fraser JD. Specificity of staphylococcal superantigen-like protein 10 toward the human IgG1 Fc domain. J Immunol. 2010;184(11):6283-6292.

41. Itoh S, et al. Staphylococcal superantigen-like protein 10 (SSL10) binds to human immunoglobulin G (IgG) and inhibits complement activation via the classical pathway. Mol Immunol. 2010;47(4):932-938.

42. Smyth DS, Meaney WJ, Hartigan PJ, Smyth CJ. Occurrence of ssl genes in isolates of Staphylococcus aureus from animal infection. J Med Microbiol. 2007;56(Pt 3):418-425.

43. Zhang L, Jacobsson K, Vasi J, Lindberg M, Frykberg L. A second IgG-binding protein in Staphylococcus aureus. Microbiology (Reading, Engl). 1998;144 ( Pt 4):985-991.

44. Atkins KL, et al. S. aureus IgG-binding proteins SpA and Sbi: host specificity and mechanisms of immune complex formation Mol Immunol. 2008;45(6):1600-1611.

45. Burman JD, et al. Interaction of human complement with Sbi, a staphylococcal immunoglobulin-binding protein: indications of a novel mechanism of complement evasion by Staphylococcus aureus. J Biol Chem. 2008;283(25):17579-17593.

46. Rooijakkers SH, van Wamel WJ, Ruyken M, van Kessel KP, van Strijp JA. Anti-opsonic properties of staphylokinase. Microbes Infect. 2005;7(3):476-484.

47. Rigby KM, DeLeo FR. Neutrophils in innate host defense against Staphylococcus aureus infections. Semin Immunopathol. 2012;34(2):237-259

48. Spaan AN, van Strijp JAG, Torres VJ. Leukocidins: staphylococcal bi-component pore-forming toxins find their receptors. Nat Rev Microbiol. 2017;15(7):435-447.

49. Cassat JE, Skaar EP. Metal ion acquisition in Staphylococcus aureus: overcoming nutritional immunity. Semin Immunopathol. 2012;34(2):215-235

50. Spaan AN, et al. Staphylococcus aureus targets the duffy antigen receptor for chemokines (DARC) to lyse erythrocytes. Cell Host 
Microbe. 2015;18(3):363-370.

51. Inoshima I, et al. A Staphylococcus aureus pore-forming toxin subverts the activity of ADAM10 to cause lethal infection in mice. Nat Med. 2011;17(10):1310-1314.

52. Wilke GA, Bubeck Wardenburg J. Role of a disintegrin and metalloprotease 10 in Staphylococcus aureus alpha-hemolysin-mediated cellular injury. Proc Natl Acad Sci USA. 2010;107(30):13473-13478.

53. Powers ME, Kim HK, Wang Y, Bubeck Wardenburg J. ADAM10 mediates vascular injury induced by Staphylococcus aureus $\alpha$-hemolysin. J Infect Dis. 2012;206(3):352-356.

54. Goldmann O, Tuchscherr L, Rohde M, Medina E. $\alpha$-Hemolysin enhances Staphylococcus aureus internalization and survival within mast cells by modulating the expression of $\beta 1$ integrin. Cell Microbiol. 2016;18(6):807-819.

55. Powers ME, Becker RE, Sailer A, Turner JR, Bubeck Wardenburg J. Synergistic action of Staphylococcus aureus $\alpha$-toxin on platelets and myeloid lineage cells contributes to lethal sepsis. Cell Host Microbe. 2015;17(6):775-787.

56. Yu KO, et al. Staphylococcus aureus $\alpha$-toxin response distinguishes respiratory virus-methicillin-resistant $\mathrm{S}$. aureus coinfection in children. J Infect Dis. 2016;214(11):1638-1646.

57. Fritz SA, et al. A serologic correlate of protective immunity against community-onset Staphylococcus aureus infection. Clin Infect Dis. 2013;56(11):1554-1561.

58. Giersing BK, Dastgheyb SS, Modjarrad K, Moorthy V. Status of vaccine research and development of vaccines for Staphylococcus aureus. Vaccine. 2016;34(26):2962-2966.

59. Alonzo F, et al. CCR5 is a receptor for Staphylococcus aureus leukotoxin ED. Nature. 2013;493(7430):51-55.

60. DuMont AL, et al. Staphylococcus aureus LukAB cytotoxin kills human neutrophils by targeting the CD11b subunit of the integrin Mac-1. Proc Natl Acad Sci USA. 2013;110(26):10794-10799.

61. Spaan AN, et al. The staphylococcal toxin Panton-Valentine Leukocidin targets human C5a receptors. Cell Host Microbe. 2013;13(5):584-594.

62. Spaan AN, et al. The staphylococcal toxins $\gamma$-haemolysin AB and CB differentially target phagocytes by employing specific chemokine receptors. Nat Commun. 2014;5:5438

63. Diep BA, et al. Improved protection in a rabbit model of community-associated methicillin-resistant Staphylococcus aureus necrotizing pneumonia upon neutralization of leukocidins in addition to alpha-hemolysin. Antimicrob Agents Chemother. 2016;60(10):6333-6340.

64. Malachowa N, et al. Staphylococcus aureus leukotoxin GH promotes inflammation. J Infect Dis. 2012;206(8):1185-1193.

65. Löffler B, et al. Staphylococcus aureus panton-valentine leukocidin is a very potent cytotoxic factor for human neutrophils. PLoS Pathog. 2010;6(1):e1000715.

66. Spaan AN, et al. Differential interaction of the Staphylococcal toxins panton-valentine leukocidin and $\gamma$-hemolysin CB with human C5a receptors. J Immunol. 2015;195(3):1034-1043.

67. Holzinger D, et al. Staphylococcus aureus Panton-Valentine leukocidin induces an inflammatory response in human phagocytes via the NLRP3 inflammasome. J Leukoc Biol. 2012;92(5):1069-1081.

68. Melehani JH, James DB, DuMont AL, Torres VJ, Duncan JA. Staphylococcus aureus leukocidin A/B (LukAB) kills human monocytes via host NLRP3 and ASC when extracellular, but not intracellular. PLoS Pathog. 2015;11(6):e1004970

69. Graves SF, et al. Sublytic concentrations of Staphylococcus aureus Panton-Valentine leukocidin alter human PMN gene expression and enhance bactericidal capacity. J Leukoc Biol. 2012;92(2):361-374.

70. Ferreras M, Höper F, Dalla Serra M, Colin DA, Prévost G, Menestrina G. The interaction of Staphylococcus aureus bi-component gamma-hemolysins and leucocidins with cells and lipid membranes. Biochim Biophys Acta. 1998;1414(1-2):108-126.

71. Reyes-Robles T, Lubkin A, Alonzo F, Lacy DB, Torres VJ. Exploiting dominant-negative toxins to combat Staphylococcus aureus pathogenesis. EMBO Rep. 2016;17(3):428-440.

72. Yoong P, Torres VJ. Counter inhibition between leukotoxins attenuates Staphylococcus aureus virulence. Nat Commun $2015 ; 6: 8125$.

73. Sharma-Kuinkel, et al. Prevalence production of virulence factors in Staphylococcus aureus isolates specific IgG IgM antibody levels in S. aureus bacteremic pneumonia patients. ASM Microbe. New Orleans, LA. June 4, 2017. http://www.abstractsonline. com/pp8/\#!/4358/presentation/4968. Accessed February 27, 2018.

74. Thomsen IP, et al. Children with invasive Staphylococcus aureus disease exhibit a potently neutralizing antibody response to the cytotoxin LukAB. Infect Immun. 2014;82(3):1234-1242.

75. Thomsen IP, et al. Monoclonal antibodies against the Staphylococcus aureus bicomponent leukotoxin AB isolated following invasive human infection reveal diverse binding and modes of action. J Infect Dis. 2017;215(7):1124-1131.

76. Janesch P, et al. Selective sensitization of human neutrophils to LukGH mediated cytotoxicity by Staphylococcus aureus and IL-8. J Infect. 2017;74(5):473-483.

77. Dumont AL, et al. Characterization of a new cytotoxin that contributes to Staphylococcus aureus pathogenesis. Mol Microbiol. 2011;79(3):814-825

78. Ventura CL, et al. Identification of a novel Staphylococcus aureus two-component leukotoxin using cell surface proteomics. PLOS ONE. 2010;5(7):e11634.

79. Postma B, et al. Chemotaxis inhibitory protein of Staphylococcus aureus binds specifically to the C5a and formylated peptide receptor. J Immunol. 2004;172(11):6994-7001.

80. de Haas CJ, et al. Chemotaxis inhibitory protein of Staphylococcus aureus, a bacterial antiinflammatory agent. J Exp Med. 2004;199(5):687-695.

81. Prat C, Bestebroer J, de Haas CJ, van Strijp JA, van Kessel KP. A new staphylococcal anti-inflammatory protein that antagonizes the formyl peptide receptor-like 1. J Immunol. 2006;177(11):8017-8026.

82. Prat C, Haas PJ, Bestebroer J, de Haas CJ, van Strijp JA, van Kessel KP. A homolog of formyl peptide receptor-like 1 (FPRL1) inhibitor from Staphylococcus aureus (FPRL1 inhibitory protein) that inhibits FPRL1 and FPR. J Immunol. 2009;183(10):6569-6578.

83. Bestebroer J, et al. Staphylococcal SSL5 inhibits leukocyte activation by chemokines and anaphylatoxins. Blood. 2009;113(2):328-337.

84. Brinkmann V, et al. Neutrophil extracellular traps kill bacteria. Science. 2004;303(5663):1532-1535. 
85. Berends ET, Horswill AR, Haste NM, Monestier M, Nizet V, von Köckritz-Blickwede M. Nuclease expression by Staphylococcus aureus facilitates escape from neutrophil extracellular traps. J Innate Immun. 2010;2(6):576-586.

86. Thammavongsa V, Missiakas DM, Schneewind O. Staphylococcus aureus degrades neutrophil extracellular traps to promote immune cell death. Science. 2013;342(6160):863-866.

87. Olson ME, et al. Staphylococcus aureus nuclease is an SaeRS-dependent virulence factor. Infect Immun. 2013;81(4):1316-1324.

88. Schilcher K, Andreoni F, Uchiyama S, Ogawa T, Schuepbach RA, Zinkernagel AS. Increased neutrophil extracellular trap-mediated Staphylococcus aureus clearance through inhibition of nuclease activity by clindamycin and immunoglobulin. $J$ Infect Dis. 2014;210(3):473-482.

89. Wang R, et al. Identification of novel cytolytic peptides as key virulence determinants for community-associated MRSA. Nat Med. 2007;13(12):1510-1514.

90. Kobayashi SD, et al. Comparative analysis of USA300 virulence determinants in a rabbit model of skin and soft tissue infection J Infect Dis. 2011;204(6):937-941.

91. Kretschmer D, et al. Human formyl peptide receptor 2 senses highly pathogenic Staphylococcus aureus. Cell Host Microbe. 2010;7(6):463-473.

92. Cassat JE, et al. A secreted bacterial protease tailors the Staphylococcus aureus virulence repertoire to modulate bone remodeling during osteomyelitis. Cell Host Microbe. 2013;13(6):759-772.

93. Loughran AJ, et al. Impact of sarA and phenol-soluble modulins on the pathogenesis of osteomyelitis in diverse clinical isolates of Staphylococcus aureus. Infect Immun. 2016;84(9):2586-2594.

94. Rautenberg M, Joo HS, Otto M, Peschel A. Neutrophil responses to staphylococcal pathogens and commensals via the formyl peptide receptor 2 relates to phenol-soluble modulin release and virulence. FASEB J. 2011;25(4):1254-1263.

95. Chatterjee SS, et al. Essential Staphylococcus aureus toxin export system. Nat Med. 2013;19(3):364-367.

96. Cantor H, et al. Immunoregulatory effects of superantigens: interactions of staphylococcal enterotoxins with host MHC and non-MHC products. Immunol Rev. 1993;131:27-42.

97. Lee LY, et al. The Staphylococcus aureus Map protein is an immunomodulator that interferes with T cell-mediated responses. $J$ Clin Invest. 2002;110(10):1461-1471.

98. Nygaard TK, et al. Alpha-toxin induces programmed cell death of human T cells, B cells, and monocytes during USA300 infection. PLoS ONE. 2012;7(5):e36532.

99. Sanchez M, et al. O-acetylation of peptidoglycan limits helper T cell priming and permits Staphylococcus aureus reinfection. Cell Host Microbe. 2017;22(4):543-551.e4.

100. Milner JD, et al. Impaired T(H)17 cell differentiation in subjects with autosomal dominant hyper-IgE syndrome. Nature. 2008;452(7188):773-776.

101. Korn T, Bettelli E, Oukka M, Kuchroo VK. IL-17 and Th17 Cells. Annu Rev Immunol. 2009;27:485-517.

102. Shimada T, et al. Staphylococcus aureus evades lysozyme-based peptidoglycan digestion that links phagocytosis, inflammasome activation, and IL-1beta secretion. Cell Host Microbe. 2010;7(1):38-49.

103. Bera A, Herbert S, Jakob A, Vollmer W, Götz F. Why are pathogenic staphylococci so lysozyme resistant? The peptidoglycan O-acetyltransferase OatA is the major determinant for lysozyme resistance of Staphylococcus aureus. Mol Microbiol. 2005;55(3):778-787.

104. Wolf AJ, et al. Phagosomal degradation increases TLR access to bacterial ligands and enhances macrophage sensitivity to bacteria. J Immunol. 2011;187(11):6002-6010.

105. Brown AF, et al. Memory Th1 cells are protective in invasive Staphylococcus aureus infection. PLoS Pathog. 2015;11(11):e1005226

106. Beavers WN, Skaar EP. Neutrophil-generated oxidative stress and protein damage in Staphylococcus aureus. Pathog Dis. 2016;74(6):ftw060

107. Pelz A, Wieland KP, Putzbach K, Hentschel P, Albert K, Götz F. Structure and biosynthesis of staphyloxanthin from Staphylococcus aureus. J Biol Chem. 2005;280(37):32493-32498.

108. Mishra NN, et al. Carotenoid-related alteration of cell membrane fluidity impacts Staphylococcus aureus susceptibility to host defense peptides. Antimicrob Agents Chemother. 2011;55(2):526-531.

109. Liu GY, et al. Staphylococcus aureus golden pigment impairs neutrophil killing and promotes virulence through its antioxidant activity. J Exp Med. 2005;202(2):209-215.

110. Gao P, Davies J, Kao RYT. Dehydrosqualene desaturase as a novel target for anti-virulence therapy against Staphylococcus aureus. MBio. 2017;8(5):e01224-17.

111. Liu CI, et al. A cholesterol biosynthesis inhibitor blocks Staphylococcus aureus virulence. Science. 2008;319(5868):1391-1394

112. Chen F, et al. Small-molecule targeting of a diapophytoene desaturase inhibits S. aureus virulence. Nat Chem Biol. 2016;12(3):174-179

113. van Sorge NM, et al. Methicillin-resistant Staphylococcus aureus bacterial nitric-oxide synthase affects antibiotic sensitivity and skin abscess development. J Biol Chem. 2013;288(9):6417-6426.

114. Kono Y. The production of nitrating species by the reaction between nitrite and hypochlorous acid. Biochem Mol Biol Int. 1995;36(2):275-283.

115. Chaudhari SS, et al. Nitrite derived from endogenous bacterial nitric oxide synthase activity promotes aerobic respiration. $M B$ Bio 2017;8(4):e00887-17.

116. Dinauer MC, Orkin SH. Chronic granulomatous disease. Annu Rev Med. 1992;43:117-124.

117. Karavolos MH, Horsburgh MJ, Ingham E, Foster SJ. Role and regulation of the superoxide dismutases of Staphylococcus aureus. Microbiology (Reading, Engl). 2003;149(Pt 10):2749-2758.

118. Park B, Nizet V, Liu GY. Role of Staphylococcus aureus catalase in niche competition against Streptococcus pneumoniae. J Bacteriol. 2008;190(7):2275-2278.

119. Cosgrove $\mathrm{K}$, et al. Catalase (KatA) and alkyl hydroperoxide reductase (AhpC) have compensatory roles in peroxide stress resistance and are required for survival, persistence, and nasal colonization in Staphylococcus aureus. J Bacteriol. 2007;189(3):1025-1035.

120. Khan Z, et al. Angiotensin-converting enzyme enhances the oxidative response and bactericidal activity of neutrophils. Blood. 
2017;130(3):328-339.

121. Carreau A, El Hafny-Rahbi B, Matejuk A, Grillon C, Kieda C. Why is the partial oxygen pressure of human tissues a crucial parameter? Small molecules and hypoxia. J Cell Mol Med. 2011;15(6):1239-1253.

122. Yarwood JM, McCormick JK, Schlievert PM. Identification of a novel two-component regulatory system that acts in global regulation of virulence factors of Staphylococcus aureus. J Bacteriol. 2001;183(4):1113-1123.

123. Wilde AD, et al. Bacterial hypoxic responses revealed as critical determinants of the host-pathogen outcome by TnSeq analysis of Staphylococcus aureus invasive infection. PLoS Pathog. 2015;11(12):e1005341.

124. Pragman AA, Yarwood JM, Tripp TJ, Schlievert PM. Characterization of virulence factor regulation by SrrAB, a two-component system in Staphylococcus aureus. J Bacteriol. 2004;186(8):2430-2438.

125. Harrison JS, Rameshwar P, Chang V, Bandari P. Oxygen saturation in the bone marrow of healthy volunteers. Blood. 2002;99(1):394.

126. Spencer JA, et al. Direct measurement of local oxygen concentration in the bone marrow of live animals. Nature. 2014;508(7495):269-273.

127. Otto M. Staphylococcal infections: mechanisms of biofilm maturation and detachment as critical determinants of pathogenicity. Annu Rev Med. 2013;64:175-188.

128. Rom JS, et al. Impact of Staphylococcus aureus regulatory mutations that modulate biofilm formation in the USA300 strain LAC on virulence in a murine bacteremia model. Virulence. 2017;8(8):1776-1790.

129. Abdelhady W, et al. Impact of vancomycin on sarA-mediated biofilm formation: role in persistent endovascular infections due to methicillin-resistant Staphylococcus aureus. J Infect Dis. 2014;209(8):1231-1240.

130. Zielinska AK, et al. sarA-mediated repression of protease production plays a key role in the pathogenesis of Staphylococcus aureus USA300 isolates. Mol Microbiol. 2012;86(5):1183-1196.

131. Yarwood JM, Schlievert PM. Quorum sensing in Staphylococcus infections. J Clin Invest. 2003;112(11):1620-1625.

132. Atwood DN, et al. XerC Contributes to diverse forms of Staphylococcus aureus infection via agr-dependent and agr-independent pathways. Infect Immun. 2016;84(4):1214-1225.

133. Yu L, et al. A novel repressor of the ica locus discovered in clinically isolated super-biofilm-elaborating Staphylococcus aureus. MBio. 2017;8(1):e02282-16.

134. O'Gara JP. ica and beyond: biofilm mechanisms and regulation in Staphylococcus epidermidis and Staphylococcus aureus. FEMS Microbiol Lett. 2007;270(2):179-188.

135. Cerca N, et al. Molecular basis for preferential protective efficacy of antibodies directed to the poorly acetylated form of staphylococcal poly-N-acetyl-beta-(1-6)-glucosamine. Infect Immun. 2007;75(7):3406-3413.

136. Skurnik D, Cywes-Bentley C, Pier GB. The exceptionally broad-based potential of active and passive vaccination targeting the conserved microbial surface polysaccharide PNAG. Expert Rev Vaccines. 2016;15(8):1041-1053.

137. Kogan G, Sadovskaya I, Chaignon P, Chokr A, Jabbouri S. Biofilms of clinical strains of Staphylococcus that do not contain polysaccharide intercellular adhesin. FEMS Microbiol Lett. 2006;255(1):11-16.

138. Periasamy S, et al. How Staphylococcus aureus biofilms develop their characteristic structure. Proc Natl Acad Sci USA. 2012;109(4):1281-1286.

139. Wang R, et al. Staphylococcus epidermidis surfactant peptides promote biofilm maturation and dissemination of biofilm-associated infection in mice. J Clin Invest. 2011;121(1):238-248.

140. Lewis K. Persister cells. Annu Rev Microbiol. 2010;64:357-372.

141. Brötz-Oesterhelt H, et al. Dysregulation of bacterial proteolytic machinery by a new class of antibiotics. Nat Med. 2005;11(10):1082-1087.

142. Conlon BP, et al. Activated ClpP kills persisters and eradicates a chronic biofilm infection. Nature. 2013;503(7476):365-370.

143. Waters EM, Rowe SE, O'Gara JP, Conlon BP. Convergence of Staphylococcus aureus persister and biofilm research: Can biofilms be defined as communities of adherent persister cells? PLoS Pathog. 2016;12(12):e1006012.

144. An TJ, Benvenuti MA, Mignemi ME, Thomsen IP, Schoenecker JG. Pediatric musculoskeletal infection: Hijacking the acutephase response. JBJS Rev. 2016;4(9)(9).

145. Bjerketorp J, Jacobsson K, Frykberg L. The von Willebrand factor-binding protein (vWbp) of Staphylococcus aureus is a coagulase. FEMS Microbiol Lett. 2004;234(2):309-314.

146. Friedrich R, et al. Staphylocoagulase is a prototype for the mechanism of cofactor-induced zymogen activation. Nature. 2003;425(6957):535-539.

147. Cheng AG, McAdow M, Kim HK, Bae T, Missiakas DM, Schneewind O. Contribution of coagulases towards Staphylococcus aureus disease and protective immunity. PLoS Pathog. 2010;6(8):e1001036.

148. Ganesh VK, et al. A structural model of the Staphylococcus aureus ClfA-fibrinogen interaction opens new avenues for the design of anti-staphylococcal therapeutics. PLoS Pathog. 2008;4(11):e1000226.

149. Malachowa N, et al. Contribution of Staphylococcus aureus coagulases and clumping factor A to abscess formation in a rabbit model of skin and soft tissue infection. PLOS ONE. 2016;11(6):e0158293.

150. McAdow M, Kim HK, Dedent AC, Hendrickx AP, Schneewind O, Missiakas DM. Preventing Staphylococcus aureus sepsis through the inhibition of its agglutination in blood. PLoS Pathog. 2011;7(10):e1002307.

151. McAdow M, et al. Coagulases as determinants of protective immune responses against Staphylococcus aureus. Infect Immun. 2012;80(10):3389-3398.

152. Ganesh VK, et al. Lessons from the crystal structure of the S. aureus surface protein clumping factor A in complex with tefibazumab, an inhibiting monoclonal antibody. EBioMedicine. 2016;13:328-338.

153. Weems JJ, et al. Phase II, randomized, double-blind, multicenter study comparing the safety and pharmacokinetics of tefibazumab to placebo for treatment of Staphylococcus aureus bacteremia. Antimicrob Agents Chemother. 2006;50(8):2751-2755.

154. Veloso TR, et al. Prophylaxis of experimental endocarditis with antiplatelet and antithrombin agents: a role for long-term prevention of infective endocarditis in humans? J Infect Dis. 2015;211(1):72-79.

155. Bunce C, Wheeler L, Reed G, Musser J, Barg N. Murine model of cutaneous infection with gram-positive cocci. Infect Immun 1992;60(7):2636-2640. 
156. ELEK SD. Experimental staphylococcal infections in the skin of man. Ann N Y Acad Sci. 1956;65(3):85-90.

157. Singh G, Marples RR, Kligman AM. Experimental Staphylococcus aureus infections in humans. J Invest Dermatol. 1971;57(3):149-162

158. Otto M. Community-associated MRSA: what makes them special? Int J Med Microbiol. 2013;303(6-7):324-330.

159. Diep BA, et al. Polymorphonuclear leukocytes mediate Staphylococcus aureus Panton-Valentine leukocidin-induced lung inflammation and injury. Proc Natl Acad Sci USA. 2010;107(12):5587-5592.

160. Knop J, et al. Staphylococcus aureus infection in humanized mice: A new model to study pathogenicity associated with human immune response. J Infect Dis. 2015;212(3):435-444.

161. Tseng CW, et al. Increased susceptibility of humanized NSG mice to Panton-Valentine leukocidin and Staphylococcus aureus skin infection. PLoS Pathog. 2015;11(11):e1005292.

162. Prince A, Wang H, Kitur K, Parker D. Humanized mice exhibit increased susceptibility to Staphylococcus aureus pneumonia J Infect Dis. 2017;215(9):1386-1395.

163. Shultz LD, Brehm MA, Garcia-Martinez JV, Greiner DL. Humanized mice for immune system investigation: progress, promise and challenges. Nat Rev Immunol. 2012;12(11):786-798

164. Kim HK, Missiakas D, Schneewind O. Mouse models for infectious diseases caused by Staphylococcus aureus. J Immunol Methods. 2014;410:88-99. 